\title{
First Report of Ectomycorrhizal Fungus, Laccaria ochropurpurea, Associated with Castanea dentata (American Chestnut) Roots in a Mixed-Species Plantation
}

\author{
Morgan V. Ritzi, ${ }^{1,2}$ Stephen D. Russell, ${ }^{1}$ M. Catherine Aime, ${ }^{1}$ and Gordon G. McNickle ${ }^{1,2, t}$ \\ ${ }^{1}$ Department of Botany and Plant Pathology, Purdue University, West Lafayette, IN 47907 \\ ${ }^{2}$ Purdue Center for Plant Biology, Purdue University, West Lafayette, IN 47907
}

Accepted for publication 5 June 2019.

Keywords: forestry, mycology, soil microbiology, trees, restoration, basidiocarp

American chestnut (Castanea dentata [Marsh.] Borkh.) once covered the majority of the eastern deciduous forests, but now is critically endangered and rarely grows to maturity owing to chestnut blight caused by the invasive pathogen Cryphonectria parasitica (Murrill) Barr (Gauthier et al. 2013). Beneficial interactions with mutualistic ectomycorrhizae sometimes confer resistance to pathogens (Cameron et al. 2013); however, owing to their near extirpation little is known about the mycorrhizal partners of American chestnut (Palmer et al. 2008).

In fall 2017, basidiocarps of Laccaria ochropurpurea (Berk.) Peck (Fig. 1) were observed in plots of a 10-year-old American chestnut plantation near West Lafayette, Indiana $\left(40^{\circ} 26^{\prime} 42.7^{\prime \prime} \mathrm{N}\right.$, $87^{\circ} 01^{\prime} 46.0^{\prime \prime} \mathrm{W}$; plots described in Gauthier et al. 2013). Aboveground samples of the basidiocarps were collected, dried, and vouchered in Purdue's Kriebel Herbarium (PUL F23019). The identity of the species was confirmed utilizing the nuclear ribosomal internal transcribed spacer, the DNA "barcode" region for fungi, using primers recommended by Schoch et al. (2012). The resulting 772-bp sequence shared $100 \%$ identity with Laccaria ochropurpurea MF773587 (Matheny and Wolfenbarger, unpublished) and was accessioned in NCBI's GenBank (MK342409). In spring 2018, root fragments were excised from beneath three American chestnut trees in three separate plots where basidiocarps were observed. Root tips with evidence of mycorrhizal fungal colonization were pooled, extracted using a modified CTAB method (Aime et al. 2005), and sequenced to confirm both the plant host and mycorrhizal associates as follows. Plant DNA from each root sample was sequenced using primers ITS1-Plant and ITSC26A (Wen and Zimmer 1996) (GenBank nos. MK093980 to MK093985). All six 200-bp sequences generated from the root samples had $99 \%$ identity with Castanea dentata (MK093985). Fungal DNA was amplified at the ITS1 region with primers ITS1 and ITS2. Six fungal amplicons were pooled and sequenced on an Illumina MiSeq platform (GenBank nos. SRR8085518 and SRR8085519). The resulting sequences were analyzed using the AmpTK pipeline with standard parameters (Palmer et al. 2018). The third most abundant amplicon shared 99\% identity with other L. ochropurpurea collections in GenBank from

${ }^{\dagger}$ Corresponding author: G. G. McNickle; E-mail: gmcnickle@purdue.edu

The author(s) declare no conflict of interest.

C 2019 The American Phytopathological Society the eastern United States (KU685733 and JX504169) (GenBank no. MK077757). Basidiocarps of L. ochropurpurea were observed fruiting again in fall 2018 in the plantation plots.

Previous reports have identified other species in the genus Laccaria on the roots of American chestnut and also noted $L$. ochropurpurea basidiocarps near American chestnut trees (Palmer et al. 2008), but to our knowledge this is the first direct confirmation of American chestnut roots associated with L. ochropurpurea.

Owing to the severity of chestnut blight, any beneficial symbiosis could turn out to be an important restoration tool. For example, systemic acquired resistance (SAR) to Phytophthora parasitica has been shown by the arbuscular mycorrhizal fungus Glomus mosseae in tomatoes (Cordier et al. 1998). SAR has been thoroughly researched and is well understood in many herbaceous crops, but in regard to the American chestnut it is not yet understood. Indeed, after 12 years of growth, only $\sim 20 \%$ of chestnut trees have a mild blight infection (1.3 out of 3 damage score; John J. Couture, unpublished data). We suggest further studies to investigate whether this association is common, whether it confers any disease

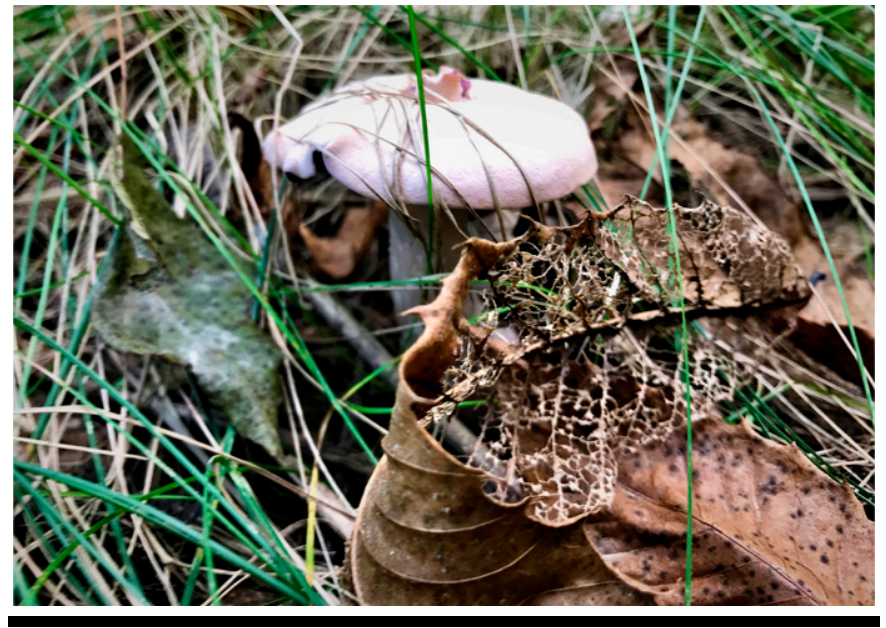

FIGURE 1

Photograph of Laccaria ochropurpurea (Berk.) Peck basidiocarps and Castanea dentata (Marsh.) Borkh leaf in American chestnut plots, at Martel Forest, Tippecanoe County, Indiana. September 5, 2017. 
resistance, and if this mutualistic association could be employed in restoration efforts for the American chestnut.

\section{Literature Cited}

Aime, M. C., Vilgalys, R., and Miller, O. K., Jr. 2005. The Crepidotaceae (Basidiomycota, Agaricales): Phylogeny and taxonomy of the genera and revision of the family based on molecular evidence. Am. J. Bot. 92:74-82.

Cameron, D. D., Neal, A. L., van Wees, S. C. M., and Ton, J. 2013. Mycorrhizainduced resistance: More than the sum of its parts? Trends Plant Sci. 18: 539-545.

Cordier, C., Gianinazzi, M., Gianinazzi-Pearson, J., Pozo, S., and Barea, V. 1998. Cell defense responses associated with localized and systemic resistance to Phytophthora parasitica induced in tomato by an arbuscular mycorrhizal fungus. Mol. Plant-Microbe Interact. 11:1017-1028.
Gauthier, M.-M., Zellers, K. E., Löf, M., and Jacobs, D. F. 2013. Inter- and intraspecific competitiveness of plantation-grown American chestnut (Castanea dentata). For. Ecol. Manage. 291:289-299.

Palmer, J., Lindner, M., and Volk, D. 2008. Ectomycorrhizal characterization of an American chestnut (Castanea dentata)-dominated community in western Wisconsin. Mycorrhiza 19:27-36.

Palmer, J. M., Jusino, M. A., Banik, M. T., and Lindner, D. L. 2018. Nonbiological synthetic spike-in controls and the AMPtk software pipeline improve mycobiome data. PeerJ 6:e4925.

Schoch, C. L., Seifert, K. A., Huhndorf, S., Robert, V., Spouge, J. L., Levesque, C. A., Chen, W., and Fungal Barcoding Consortium. 2012. Nuclear ribosomal internal transcribed spacer (ITS) region as a universal DNA barcode marker for Fungi. Proc. Natl. Acad. Sci. 109:6241-6246.

Wen, J., and Zimmer, E. A. 1996. Phylogeny and biogeography of Panax L. (the ginseng genus, Araliaceae): Inferences from ITS sequences of nuclear ribosomal DNA. Mol. Phylogenet. Evol. 6:167-177. 